\title{
UNJUK KERJA MESIN PEMOTONG PADI TIPE GLX 328-RH PADA BEBERAPA RPM DI LAHAN KERING
}

\section{PERFORMANCE TEST OF PADDY CUTTING MACHINE TYPE GLX 328-RH IN SOME RPM ON DRY LAND}

\author{
Muhamad Teguh Angga Saputra ${ }^{1} \bowtie$, Siti Suharyatun ${ }^{1}$, Sandi Asmara ${ }^{1}$, Agus Haryanto ${ }^{1}$ \\ ${ }^{1}$ Jurusan Teknik Pertanian Universitas Lampung \\ $\bowtie$ komunikasi penulis, email: muhamadteguhanggasaputra@gmail.com \\ DOI:http://dx.doi.org/10.23960/jtep-lv7i3.168-174
}

Naskah ini diterima pada 03 April 2018; revisi pada 04 Juni 2018; disetujui untuk dipublikasikan pada 16 Agustus 2018

\begin{abstract}
Agricultural tools and machinery have rapidly developed, start from the traditional way called ani-ani that only cut panicle of paddy until the combine harvester which can do cutting, threshing, then packing of paddy. Financial condition and differentiation of paddy field area make the farmers have to choose an appropriate machine. One of alternative machine that can be used for the field that is not too wide is paddy cutting machine (paddy mower) type GLX 328-RH. This research aims to discover its work capacity, paddy losses, and fuel consumption, also the economic analysis of the use of paddy cutting machine type GLX 328-RH for harvesting. This research consists of three main stages, namely preparation of machine and paddy field, testing of machine performance and data analysis. The observed parameters are the working capacity of the mechine, the percenage of grain loss and fuel consumption. The results show that work capacity of the mower with RPM 3863 0,019 ha/hour and RPM 5000 $0,022 \mathrm{ha} /$ hour is higher than using sickle 0,013 ha/hour. Losses tend to decrease with increasing speed in RPM. Losses at $R P M 1824=1,91 \%, R P M 3863=0,84 \%, R P M 5000=0,56 \%$. Fuel consumption at $R P M 1824=100,78$ l/ha, RPM $3863=49 \mathrm{l} / \mathrm{ha}$, and RPM $5000=35,67 \mathrm{l} / \mathrm{ha}$. Break even point of the mower type GLX 328-RH is 4,64 ha/year. NPV paddy cutting machine type GLX 328-RH is Rp 1.006.632,03/year, B/C Ratio paddy cutting machine is 1,025. IRR machine is $39,103 \%$, and pay backperiode reached on 2,07 year.
\end{abstract}

Keywords: Paddy, paddy cutting machine, work capacity, performance test

\begin{abstract}
ABSTRAK
Perkembangan alat mesin pertanian sangat pesat, mulai dari alat tradisional ani-ani yang hanya dapat memotong malai padi hingga combine harvester yang dapat memotong, merontokan, sampai pengarungan gabah. Kondisi keuangan dan lahan yang berbeda menyebabkan petani harus memilih mesin tepat guna. Salah satu alternatif mesin yang dapat digunakan untuk lahan yang tidak terlalu luas yaitu mesin pemotong padi (paddy mower) tipe GLX 328-RH. Tujuan dari penelitian ini untuk mengetahui kapasitas kerja, kehilangan gabah (losses), dan konsumsi bahan bakar serta analisis ekonomi penggunaan mesin pemotong padi tipe GLX 328-RH untuk pemanenan. Penelitian ini terdiri dari tiga tahapan utama, yaitu persiapan mesin dan lahan, pengujian performansi mesin dan analisis data. Parameter yang diamati adalah kapasitas kerja mesin, persentase kehilangan gabah, dan konsumsi bahan bakar. Hasil penelitian menunjukan bahwa kapasitas kerja mesin pemotong padi dengan RPM 3863 0,019 ha/jam dan RPM 5000 0,022 ha/jam lebih besar dibanding sabit 0,013 ha/jam. Losses cenderung menurun dengan meningkat nya kecepatan RPM. Losses pada RPM $1824=1,91 \%$, RPM $3863=0,84 \%$, RPM $5000=0,56 \%$. Konsumsi bahan bakar pada RPM $1824=100,78 \mathrm{l} / \mathrm{ha}$, RPM $3863=49 \mathrm{l} / \mathrm{ha}$, dan RPM $5000=$ 35,67 l/ha. Nilai break even point (BEP) penggunaan mesin pemotong padi tipe GLX 328-RH sebesar 4,64ha. NPV mesin pemotong padi tipe GLX 328-RH sebesar Rp 1.006.632,03/year. B/C Ratio mesin pemotong padi sebesar 1,025. IRR mesin sebesar 39,103\%, dan pay back periode tercapai pada 2,07 tahun.
\end{abstract}

Kata Kunci: Padi, mesin pemotong padi, kapasitas kerja, unjuk kerja 


\section{PENDAHULUAN}

Panen adalah salah satu kegiatan budidaya tanaman yang perlu mendapat perhatian khusus, Pada saat pemanenan ialah proses yang sangat kritis, dikarenakan pada tanaman tertentu, apabila saat panen terjadi keterlambatan, maka kualitas maupun kuantitas akan hasil atau produksinya akan menurun dan bahkan dapat mengalami kerusakan total.

Pada tanaman padi pemanenan dilakuan pada saat $95 \%$ gabah sudah menguning dan daun bendera telah mengering. Umur optimal malai 30 - 35 hari terhitung sejak hari sesudah berbunga (HSB), kadar air berkisar $21-26 \%$, dan kerontokan gabah sekitar 16 - $30 \%$ (cara mengukurnya dengan meremas malai dengan tangan) (Direktorat Jenderal Tanaman Pangan dan Hortikultura, 1999).

Penanganan panen dan pascapanen memiliki kontribusi nyata dalam mengamankan produksi beras nasional. Kehilangan hasil panen dan pascapanen akibat ketidaksempurnaan penanganan pascapanen mencapai $20,51 \%$, yang terdiri atas kehilangan saat pemanenan $9,52 \%$, perontokan $4,78 \%$, pengeringan $2,13 \%$, dan penggilingan $2,19 \%$. Jika dikonversikan terhadap produksi padi nasional yang mencapai 54,34 juta ton, kehilangan hasil tersebut setara dengan Rp15 triliun lebih (Purwanto, 2011).

Penggunaan alat pemanen tradisional saat ini dinilai kurang efisien dimana dalam pengerjaannya harus dilakukan oleh lebih dari satu tenaga kerja dan pemanenan membutuhkan waktu yang lama. Apabila dibandingkan dengan alat pemanen modern yang sudah banyak di pasar yaitu mesin pemotong padi tipe GLX 328-RH.

Secara nasional rata-rata produktivitas padi di lahan kering masih jauh di bawah produktivitas padi sawah, rendahnya produktivitas padi di lahan kering disebabkan banyaknya permasalahan yang dihadapi petani seperti kekeringan, tanah yang masam, dan penyakit. Menurut Tjahjohutomo (2008) penanganan panen cara petani dengan menggunakan alat konvensional yaitu sabit, perontokan dengan gebot, pengeringan di lantai jemur, dan penggilingan gabah dengan alat konvensional, menyebabkan susut hasil
21,09\%. Untuk membantu petani dilahan kering dalam meminimalisir tingkat kehilangan maka digunakanlah mesin pemotong padi tipe GLX 328-RH.

Penggunaan mesin pemotong padi tipe GLX 328RH perlu dikaji agar diketahui kinerja mesin tersebut. Pengujian mesin pemotong padi ini bertujuan untuk mendapatkan informasi mengenai kapasitas kerja, pengaruhnya terhadap menurunkan kehilangan hasil pemanenan (losses), serta seberapa efisien alat mesin pemotong tesebut untuk digunakan.

Tujuan dari penelitian ini adalah mengetahui pengaruh kecepatan pemotongan RPM terhadap kapasitas kerja mesin, mengetahui pengaruh RPM pada penggunaan mesin pemotong padi terhadap tingkat kehilangan padi (losses), mengetahui pengaruh RPM pada penggunaan mesin pemotong terhadap bahan bakar yang digunakan pada waktu pemanenan di lahan kering, dan menghitung analisis ekonomi pemanenan padi per hektar dengan menggunakan mesin pemotong padi tipe GLX 328-RH di lahan kering.

\section{BAHAN DAN METODE}

Penelitian ini dilaksanakan di Desa Singaparna, Kelurahan Sendang Ayu, Kecamatan Padang Ratu, Lampung Tengah dan di Laboratorium Daya dan Alat Mesin Pertanian Jurusan Teknik Pertanian Fakultas Pertanian Universitas Lampung pada bulan November 2017. Alat yang digunakan pada penelitian ini yaitu : mesin paddy mower, mesin pemotong padi 2 tak dengan tipe GLX 328-RH, digital tachometer, timbangan digital, rol meter, stopwatch, gelas ukur. Sedangkan bahan yang digunakan yaitu: tanaman padi yang siap dipanen pada lahan kering, terpal, bahan bakar, oli samping, kantong plastik, karung, dan tali raffia.

\subsection{Tahapan Penelitian}

\subsubsection{Persiapan}

1. Mesin Pemotong Tipe GLX 328-RH

Penentuan tiga besaran RPM yang akan digunakan untuk memotong padi. RPM yang digunakan yaitu RPM 1824, RPM 3863, dan RPM 5000. 


\section{Pengukuran Luasan Lahan}

Luasan lahan yang digunakan untuk penelitian ini yakni $3 \mathrm{~m}$ x $10 \mathrm{~m}$, sebanyak sembilan luasan $30 \mathrm{~m}^{2}$ diukur kemudian dipetakkan menggunakan tali raffia.

3. Membungkus batang padi dengan kantong Plastik

Pembungkusan dilakukan pada setiap rumpun padi dengan menggunakan kantong plastik.

\subsubsection{Proses Pemanenan dan Perontokan}

Proses pemanenan dilakukan dengan 3 tingkatan rpm yang sudah ditentukan, untuk satu tingkat rpm dilakukan pengulangan sebanyak 3 kali. Setelah selesai pemanenan, dilakukan pengumpulan dan pelepasan kantong plastik dari malai padi. Kemudian dilakukan perontokan menggunakan gebot.

\subsubsection{Parameter Pengamatan}

1. Kapasitas Kerja Mesin

Luasan lahan dibagi waktu yang dibutuhkan untuk proses pemotongan padi ( $\mathrm{K}_{\mathrm{KM}}$, ha/jam). Kapasitas kerja mesin dapat dicari dengan menggunakan persamaan berikut:

$$
\begin{aligned}
\mathrm{K}_{\mathrm{KM}}=\frac{A}{\mathrm{t}} \\
\text { dimana : } \\
\mathrm{K}_{\mathrm{KM}}=\text { Kapasitas kerja mesin (ha/jam) } \\
\mathrm{A}^{\quad}=\text { Luasan areal panen (ha) } \\
\mathrm{t} \quad=\text { Waktu (jam) }
\end{aligned}
$$

\section{Konsumsi bahan bakar}

Bahan bakar yang dibutuhkan untuk panen dalam satu luasan lahan $\left(\mathrm{K}_{\mathrm{BB}}\right.$, liter $)$. Kebutuhan bahan bakar dicari denngan menggunakan persamaan berikut:

$$
\mathrm{K}_{\mathrm{BB}}=\frac{\mathrm{BH}}{\mathrm{A}}
$$

dimana :

$$
\begin{aligned}
& \mathrm{K}_{\mathrm{BB}}=\text { Konsumsi bahan bakar (L/ha) } \\
& \mathrm{BB}=\text { Kebutuhan bahan bakar (L) } \\
& \mathrm{A}=\text { Luasan area panen (ha) }
\end{aligned}
$$

3. Jumlah kehilangan padi atau losses

Jumlah padi yang rontok pada saat proses pemanenan $\left(\mathrm{m}_{1} \mathrm{~kg}\right)$. Kehilangan padi (losses) dapat dicari dengan menggunakan persamaan berikut:

$$
\mathrm{P}_{\mathrm{KP}}=\frac{\mathrm{m}_{\mathrm{l}}}{\left(\mathrm{m}_{\mathrm{p}}+\mathrm{m}_{1}\right]} \times 100 \%
$$

$$
\begin{aligned}
& \text { dimana: } \\
& \mathrm{P}_{\mathrm{KP}}=\text { Persentase kehilangan padi }(\%) \\
& \mathrm{m}_{1}=\text { Padi terontok dalam plastik }(\mathrm{kg}) \\
& \mathrm{m}_{\mathrm{p}}=\text { Jumlah padi yang dipanen }(\mathrm{kg})
\end{aligned}
$$

\subsubsection{Analisis Data}

Penelitian ini dianalisis menggunakan Rancangan Acak Lengkap (RAL) untuk mengetahui pengaruh kecepatan putar pemotong terhadap kapasitas kerja alat serta tingkat kehilangan (losses). Dan apabila berpengaruh, maka akan dilanjutkan dengan uji lanjut. Hasil penelitian juga disajikan dalam bentuk tabel dan grafik.

Perhitungan biaya untuk alat dan mesin pertanian dikenal dengan dua komponen biaya, yaitu biaya tetap dan biaya tidak tetap. Unsur dari biaya tetap yaitu biaya penyusutan (Persamaan 4). Sedangkan, untuk biaya tidak tetap antara lain biaya bahan bakar (Persamaan 5), biaya oli samping (Persamaan 6), biaya perbaikan dan pemeliharann (Persamaan 7), dan biaya operator (Persamaan 8). Asumsi penggunaan mesin adalah 648 jam per tahun, umur ekonomis 5 tahun, upah operator $\mathrm{Rp}$ 80.000/hari, suku bunga 10,4\%/tahun, harga bahan bakar premium Rp 7000,000/liter, dan harga oli samping Rp 25.000/liter.

$$
\begin{aligned}
& \mathrm{D}=(\mathrm{P}-\mathrm{S}) \times \mathrm{crf} \\
& \mathrm{Bbb}=\mathrm{Kbb} \times \mathrm{Hbb} \times \mathrm{Kkm} \\
& \mathrm{Bos}=\mathrm{Kos} \times \mathrm{Hos} \times \mathrm{Kkm} \\
& \mathrm{Bpp}=\mathrm{P} \times \frac{\mathrm{m}}{720 \mathrm{jam}} \\
& \text { Bop }=\text { Op } \times \text { Uop }
\end{aligned}
$$

dimana :

$$
\begin{aligned}
& \mathrm{D}=\text { Biaya penyusutan tiap tahun (Rp/tahun) } \\
& \mathrm{P}=\text { Purchase price }(\mathrm{Rp}) \\
& \mathrm{S}=\text { Nilai akhir }(10 \% \text { dari } \mathrm{P})(\mathrm{Rp}) \\
& \mathrm{n}=\text { Perkiraan umur ekonomi (jam) } \\
& \mathrm{i}=\text { Suku bunga(\%/tahun) } \\
& \mathrm{Bbb}=\text { Biaya bahan bakar }(\mathrm{Rp} / \mathrm{ha}) \\
& \mathrm{Kbb}=\text { Kebutuhan bahan bakar }(\mathrm{L} / \mathrm{ha}) \\
& \mathrm{Hbb}=\text { Harga bahan bakar }(\mathrm{Rp} / \mathrm{liter}) \\
& \mathrm{Kkm}=\text { Kapasitas kerja mesin (ha/jam) } \\
& \mathrm{Bos}=\text { Biaya oli samping (Rp) } \\
& \mathrm{Kos}=\text { Kebutuhan oli samping (liter) } \\
& \mathrm{Hos}=\text { Harga oli samping (Rp/liter) } \\
& \mathrm{m}=\text { nilai pemeliharaan (rata-rata } 5 \%) \\
& \mathrm{Bop}=\text { Biaya operator }(\mathrm{Rp}) \\
& \mathrm{Op}=\text { Jumlah operator } \\
& \mathrm{Uop}=\text { Upah operator }(\mathrm{Rp} / \text { Hari) } \\
& \mathrm{Bpp}=\text { Biaya Perbaikan dan Pemeliharaan(Rp/ } \\
& \text { jam }
\end{aligned}
$$


Biaya total adalah biaya keseluruhan yang diperlukan untuk mengoprasikan suatu mesin pertanian, biaya ini merupakan penjumlahan dari biaya tetap dan biaya tidak tetap. yang ditunjukan pada Persamaan 9. BEP (Break Even Point) adalah suatu kondisi titik impas dimana pengeluaran sama dengan pendapatan.

$$
\mathrm{TC}=\mathrm{VC}+\mathrm{FC}
$$

dimana:

$$
\begin{aligned}
& \mathrm{TC}=\text { Biaya Total }(\mathrm{Rp} / \mathrm{Ha}) \\
& \mathrm{FC}=\text { Total Biaya tetap }(\mathrm{Rp} / \mathrm{Ha}) \\
& \mathrm{VC}=\text { Total Biaya Tidak Tetap }(\mathrm{Rp} / \mathrm{Ha})
\end{aligned}
$$

\subsection{Analisis kelayakan}

A. Net Present Value (NPV)

Net present value (NPV) adalah jumlah selisih antara nilai terkini penerimaan (Benefit) dan nilai terkini dari pengeluaran (Cost) (Persamaan 10). Jika NPV e" 0, maka mesin paddy mower layak digunakan. Sedangkan, jika NPV e" 0, maka mesin paddy mower tidak layak digunakan.

$$
\mathrm{NPV}=\mathrm{B}-\mathrm{C}
$$

Dimana :

$$
\begin{aligned}
& \mathrm{NPV}=\text { Net present value } \\
& \mathrm{B}=\text { Nilai total penerimaan }(\mathrm{Rp} / \mathrm{tahun}) \\
& \mathrm{C}=\text { Nilai total pengeluaran (Rp/tahun) }
\end{aligned}
$$

\section{B. Benefit Cost Ratio (B/C Ratio)}

Metode yang digunakan untuk mendapatkan hasil perbandingkan antara Benefit terhadap Cost digunakan rumus pada Persamaan 11. Jika B/C Ratio >1, maka penggunaan mesin paddy mower tersebut layak.Sedangkan jika B/C Ratio $<1$, maka penggunaan mesin paddy mower tersebut tidak layak (Pramudya, 2001).

$$
\mathrm{B} / \mathrm{C} \text { Ratio }=\mathrm{B} / \mathrm{C}
$$

Dimana :

$B=$ Nilai total penerimaan sekarang $(R p)$

$\mathrm{C}=$ Nilai total pengeluaran sekarang $(\mathrm{Rp})$

\section{Internal Rate Of Return (IRR)}

Nilai IRR (Persamaan 12) diperoleh dengan menggunakan perhitungan coba-coba (trail and error) karena tidak dapat iselesaikan secara langsung (Pramudya, 2001).

$$
I R R=i^{\prime}+\frac{N^{N P V}}{N^{\prime} V^{\prime} \text { NPV }^{\prime \prime}}\left(i^{\prime \prime}-i^{\prime}\right)
$$

\section{Pay Back Periode (PBP)}

Pay Back Periode merupakan jangka waktu dari pengembalian modal dalam suatu usaha bisnis.
Nilai PBP diperoleh dengan menggunakan persamaan 13.

$$
\mathrm{PBP}=\frac{F}{\pi}
$$

Dimana :

$$
\begin{aligned}
& \mathrm{PBP}=\text { Pay Back Periode (tahun) } \\
& \mathrm{P}=\text { Harga pembelian alat }(\mathrm{Rp}) \\
& \Pi \quad=\text { Pendapatan }(\mathrm{Rp} / \text { tahun })
\end{aligned}
$$

\section{HASIL DAN PEMBAHASAN}

\subsection{Kapasitas Kerja Mesin Pemotong Padi Tipe GLX 328-RH}

Padi varietas Inpago 8 ditanam pada lahan kering dengan kadar lengas tanah pada saat pemanenan sebesar $26,96 \%$ dengan jarak $25 \mathrm{~cm}$ x $25 \mathrm{~cm}$, rata-rata tinggi tanaman $110,5 \mathrm{~cm}$ dan jumlah anakan 21 batang. Hasil kapasitas kerja mesin pemotong padi Tipe GLX 328-RH dan kapasitas kerja sabit (Gambar 1) menunjukan bahwa kapasitas kerja mesin pada RPM 1824 sebesar 0,00933 ha/jam, pada RPM 3863 sebesar 0,01867 ha/jam, dan pada RPM 5000 sebesar 0,02155 ha/jam. Kapasitas kerja mesin optimal pada RPM 5000, kapasitas itu lebih tinggi dibandingkan dengan kapasitas sabit yang hanya sebesar 0,01296 ha/jam. Namun kapsitas kerja mesin GLX 328-RH lebih rendah dibandingkan dengan mesin modified mower BBPMP yang kapasitas kerjanya sebesar 0,0563 $\mathrm{Ha} / \mathrm{jam}$ (BBPMP,2016). Hal ini dikarenakan motor penggerak mesin pemotong padi modified mower BBPMP lebih besar (2 HP) dibandingkan dengan tipe GLX 328-RH (1 HP). Analisis sidik ragam juga menunjukan bahwa RPM berpengaruh terhadap kapasitas kerja mesin ditunjukkan dalam Tabel 1 dan Tabel 2.

\subsection{Persentase Kehilangan Gabah (Losses)}

Hasil pengambilan sampel gabah yang rontok di dalam plastik yang diikat pada batang padi setiap gabah padi yang rontok di dalam plastik diambil dan dikumpulkan, kemudian ditimbang. Hasil pengujian (Gambar 2) menunjukan bahwa tingkat kehilangan gabah pada RPM 1824 sebesar 1,91\%, pada RPM 3863 sebesar 0,84\%, dan pada RPM 5000 sebesar 0,56\%. Pada RPM 1824 menunjukan jumlah losses yang sangat tinggi, hal ini diakibatkan oleh putaran pisau yang sering menyangkut pada batang padi sehingga getaran yang terjadi pada batang padi 
Unjuk Kerja Mesin Pemotong.... (Saputra, dkk)

Tabel 1. Hasil analisis ragam pengaruh RPM terhadap kasitas kerja mesin

\begin{tabular}{lcccccc}
\hline \multirow{2}{*}{ SK } & \multirow{2}{*}{ Db } & \multirow{2}{*}{ JK } & \multirow{2}{*}{ KT } & Fhitung & \multicolumn{2}{c}{ Ftabel } \\
\cline { 6 - 7 } & & & & & $\mathbf{0 , 0 5}$ & $\mathbf{0 , 0 1}$ \\
\hline Perlakuan & 2 & 0,000245 & 0,000122487 & 133,659620 & 5,14325 & 10,9248 \\
Sisa & 6 & 0,000005 & 0,000000916 & & & \\
\hline Total & $\mathbf{8}$ & $\mathbf{0 , 0 0 0 2 5 0}$ & & & & \\
\hline
\end{tabular}

F hitung > F tabel, maka perlakuan RPM berpengaruh terhadap kapasitas kerja mesin.

Tabel 2. Hasil uji BNT pengaruh RPM terhadap kapasitas kerja mesin

\begin{tabular}{cccc}
\hline BNT & RPM 1824 & RPM 3863 & RPM 5000 \\
\hline $5 \%$ & $\mathrm{~A}$ & $\mathrm{~B}$ & $\mathrm{C}$ \\
$1 \%$ & $\mathrm{~A}$ & $\mathrm{~B}$ & $\mathrm{BC}$ \\
\hline
\end{tabular}

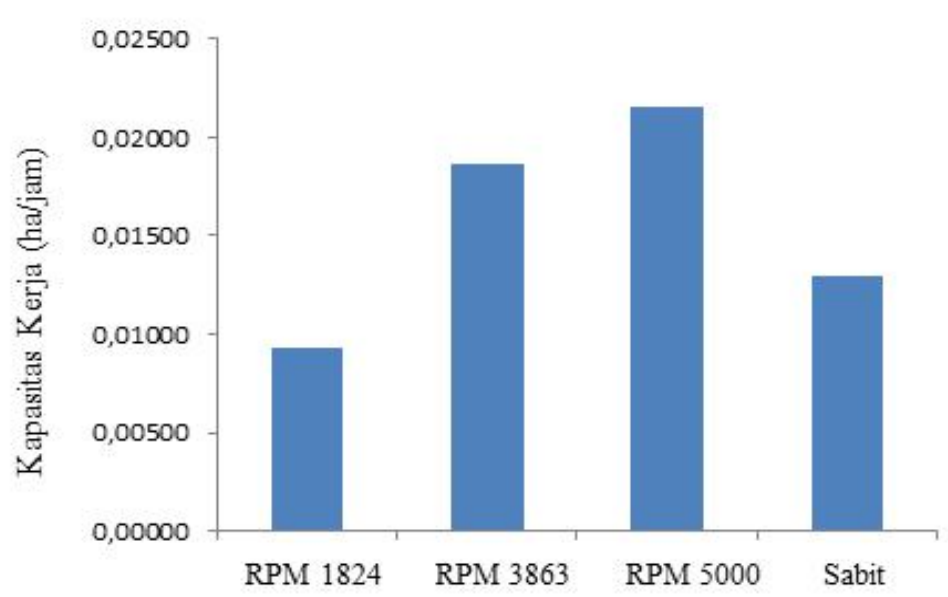

Gambar 1. Grafik kapasitas kerja mesin pemotong padi Tipe GLX 328-RH dan sabit

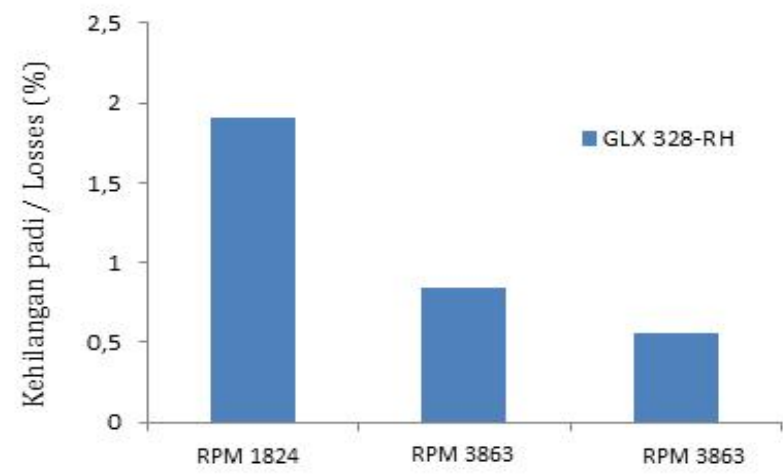

Gambar 2. Grafik persentase kehilangan gabah (losses)

mengakibatkan rontoknya gabah dari batang padi. Semakin cepat putaran pisau maka semakin cepat pula pisau memotong batang padi dan semakin sedikit gabah yang terontok.

Nilai tingkat kehilangan padi (losses) menggunakan mesin pemotong Tipe GLX 328RH sebesar 0,56\% lebih tinggi dibandingkan dengan mesin modifed mower BBPMP yang tingkat kehilangan padi (losses) sebesar 0,34\%.
Hal ini dipegaruhi oleh varietas padi yang dipanen, BBPMP menggunakan varietas IR64 yang tahan akan kerontokan, sedangkan pada penelitian ini menggunakan varietas Inpago 8 yang tingkat kerontokannya sedang (BBP, 2013). Analisis sidik ragam juga menunjukan bahwa RPM berpengaruh terhadap tingkat kehilangan gabah (losses) ditampilkan dalam Tabel 3 dan Tabel 4. 
Tabel 3. Hasil analisis ragam pengaruh RPM terhadap tingkat kehilangan gabah (losses)

\begin{tabular}{lcccccc}
\hline \multicolumn{1}{c}{ SK } & DB & JK & KT & F Hitung & \multicolumn{2}{c}{ F Tabel } \\
\cline { 6 - 7 } & & & & & $\mathbf{5 \%}$ & $\mathbf{1 \%}$ \\
\hline Perlakuan & 2 & 40659,6 & 20329,8 & 15,594 & 9,552094 & 30,81652 \\
Sisa & 3 & 3911,73 & 1303,9 & & & \\
\hline Total & $\mathbf{5}$ & $\mathbf{4 4 5 7 1 , 3}$ & & & & \\
\hline
\end{tabular}

F hitung > F tabel 5\%, maka perlakuan RPM berpengaruh terhadap tingkat kehilangan gabah (losses)

Tabel 4. Hasil uji BNT pengaruh RPM terhadap Losses

\begin{tabular}{cccc}
\hline BNT & RPM 5000 & RPM 3863 & RPM 1824 \\
\hline $5 \%$ & $\mathrm{~A}$ & $\mathrm{AB}$ & $\mathrm{C}$ \\
$1 \%$ & $\mathrm{~A}$ & $\mathrm{AB}$ & $\mathrm{C}$ \\
\hline
\end{tabular}

Tabel 5. Hasil analisis ragam pengaruh RPM terhadap konsumsi bahan bakar

\begin{tabular}{lcccccc}
\hline \multicolumn{1}{c}{ SK } & DB & JK & KT & F Hitung & \multicolumn{2}{c}{ F Tabel } \\
\cline { 5 - 7 } & & & & & $\mathbf{5 \%}$ & $\mathbf{1 \%}$ \\
\hline Perlakuan & 2 & 65474,67 & 32737,33 & 313,11 & 5,14325 & 10,9248 \\
Sisa & 6 & 627,33 & 104,56 & & & \\
\hline Total & $\mathbf{8}$ & $\mathbf{6 6 1 0 2}$ & & & & \\
\hline
\end{tabular}

F hitung $>$ F tabel, maka perlakuan RPM berpengaruh terhadap konsumsi bahan bakar.

Tabel 6. Hasil uji BNT pengaruh RPM terhadap konsumsi Bahan Bakar

\begin{tabular}{cccc}
\hline BNT & RPM 5000 & RPM 3863 & RPM 1824 \\
\hline $5 \%$ & A & B & C \\
$1 \%$ & A & B & C \\
\hline
\end{tabular}

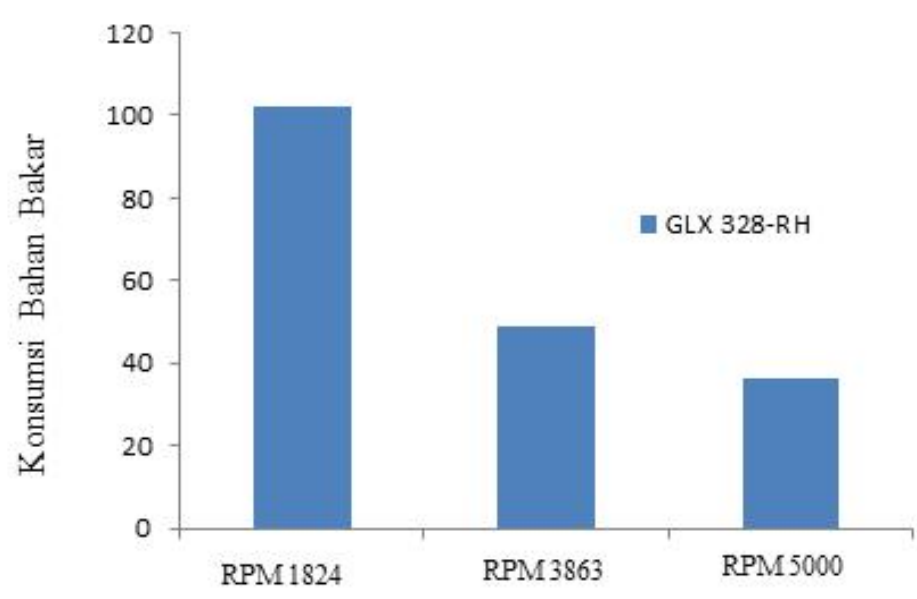

Gambar 3. Grafik konsumsi bahan bakar

\subsection{Konsumsi Bahan Bakar}

Hasil kebutuhan bahan bakar yang diperlukan untuk memotong padi (Gambar 3 ). Setelah proses pemotongan padi selesai dilakukan untuk satu petakan, penambahan bahan bakar pada tangki yang diterpakai itulah yang menjadi konsumsi bahan bakar. Pada gambar 3 menunjukan bahwa konsumsi bahan bakar pada RPM 1824 sebesar 100,78 liter/Ha, pada RPM 3863 sebesar 49 liter/Ha, dan pada RPM 5000 sebesar 35,67 liter/Ha. Analisis sidik ragam juga menunjukan bahwa RPM berpengaruh terhadap konsumsi bahan bakar ditampilkan dalam Tabel 5 dan Tabel 6. 


\subsection{Analisis Biaya Pemanenan Padi Per Hektar}

Biaya panen padi dengan menggunakan mesin pemotong padi Tipe GLX 328-RH diperhitungkan dengan biaya operasi dan perawatan dari mesin tersebut. Biaya tersebut terdiri atas biaya tetap dan biaya tidak tetap. Komponen dari biaya tetap antara lain biaya penyusutan sebesar Rp 21.476,11/Ha. Sedangkan biaya tidak tetap antara lain biaya bahan bakar (Rp 249.670,02 /Ha), Biaya oli samping (Rp 17.748,58 / Ha), Biaya perbaikan dan pemeliharaan $(\mathrm{Rp} 4.027,98 / \mathrm{Ha})$, dan Biaya operator (Rp $464.000 / \mathrm{Ha}$ ). Biaya total dari pengoprasian mesin tersebut sebesar Rp 756.922,09 /Ha. Break even point (BEP) untuk mesin pemotong padi tipe GLX 328-RH akan tercapai pada 4,64 Ha, Nilai break even point (BEP) penggunaan mesin pemotong padi tipe GLX 328-RH sebesar 4,64ha. NPV mesin pemotong padi tipe GLX 328-RH sebesar Rp 1.006.632,03/year. B/C Ratio mesin pemotong padi sebesar 1,025. IRR mesin sebesar 39,103\%, dan pay back periode tercapai pada 2,07 tahun.

\section{KESIMPULAN DAN SARAN}

\subsection{Kesimpulan}

Adapun kesimpulan dari penelitian ini yaitu:

1. Kapasitas kerja mesin pemotong padi tipe GLX 328-RH optimal pada RPM 5000 sebesar $0,02155 \mathrm{ha} / \mathrm{jam}$.

2. Persentase kehilangan gabah terendah pada RPM 5000 sebesar $0,56 \%$

3. Konsumsi bahan bakar terendah pada RPM 5000 sebesar 35,67 l/ha.

4. Nilai break even point (BEP) penggunaan mesin pemotong padi tipe GLX 328-RH sebesar 4,64ha. NPV mesin pemotong padi tipe GLX 328-RH sebesar Rp 1.006.632,03/ year. B/C Ratio mesin pemotong padi sebesar 1,025. IRR mesin sebesar 39,103\%, dan pay back periode tercapai pada 2,07 tahun.

\subsection{Saran}

Pengoprasian mesin pemotong padi tipe GLX 328-RH ini disarankan menggunakan RPM 5000, karena pada RPM tersebut dapat menghasilkan kapasitas kerja optimal, tingkat kehilangan gabah dan konsumsi bahan bakar yang rendah.

\section{DAFTAR PUSTAKA}

[BBP]Balai Besar Penelitian Tanaman Padi. 2013 Deskripsi varietas padi. http:// bbpadi.litbang.pertanian.go.id/ indexphp/publikasi/buku/content/ item/150-deskipsi-varietas-padi-2013. 9 Januari 2018].

[BBPMP]Balai Besar Pengembangan Mekanisasi Pertanian. 2016. Uji performansi modified mower BBPMP untuk pemanenan padi di kecaatan sumber manjing wetan. Jurnal teknologi pertanian. 17 (1) : 13-20 [11 Januari 2018].

Direktorat Jenderal Tanaman dan Hortikultura.1999.Umur Optimum Pemanenan Padi. Departemen Pertanian. Direktorat Jenderal Bina Produksi Hortikultura. Jakarta.

Pramudya, B. 2001.Ekonomi Teknik. Institut Pertanian Bogor. Bogor.

Purwanto. 2011. Kehilangan pascapanen padi kita masih tinggi. http://io.ppijepang.org. Diakses tanggal [24 september 2017].

Tjahjohutomo, R. 2008. Komersialisasi inovasi teknologi hasil penelitian dan pengembangan pertanian. Disampaikan pada Work- shop Membangun Sinergi A-B-G dalam Komersialisasi Hasil Litbang Alsintan Lokal Dalam Negeri, FATETA $I P B$, Bogor, 6 Agustus 2008. Badan Penelitian dan Pengembangan Pertanian, Jakarta 